\title{
MARLI ANDRÉ - PESSOA SINGULAR, PROFESSORA, PESQUISADORA, ACADÊMICA, NOS CAMPOS DA DIDÁTICA E DA FORMAÇÃO DE PROFESSORES
}

\author{
Maria Rita N.S. OLIVEIRA \\ CEFET-MG, UFMG \\ Belo Horizonte, Minas Gerais - Brasil \\ mariarita2@cefetmg.br \\ https://orcid.org/0000-0002-3089-5939
}

\begin{abstract}
RESUMO: Este texto tem por objetivo homenagear Marli André, abordando aspectos da sua obra particularmente nos campos da Didática e da Formação de Professores. Além das marcas de uma parceria comum, teve-se como fonte produção intelectual da Marli e de autores cujas publicações tratam da obra em pauta. De início, apresentam-se aspectos do trabalho realizado por ela em espaços da administração, do ensino, da pesquisa e extensão na área educacional. Em seguida, faz-se uma leitura daquela produção, indicando algumas das suas características: coerência no compromisso com a inclusão educacional; pesquisa como fator de organicidade entre os campos de estudo mencionados e a interação entre eles; ênfase na pesquisa etnográfica; participação expressiva na constituição histórica dos campos de estudo em pauta. Termina-se afirmando o caráter coletivo e educativo do trabalho da Marli cujo legado marcam e continuarão marcando a área da educação.
\end{abstract}

PALAVRAS-CHAVE: Marli André. Didática e Formação de Professores. Pesquisa em educação.

\section{SINGULAR PERSON, TEACHER, RESEARCHER, ACADEMIC, IN DIDACTIS AND TEACHER EDUCATION FIELDS OF STUDY}

\begin{abstract}
The objective of this text is to homage Marli André, approaching aspects of her work particularly in the fields of Didactics and Teaching Education. Beyond the marks of a common partnership, it was analysed Marli's intellectual production and other authors's publication which deals with that work. Initially, aspects of the work carried through for her are presented, in administration, teaching, research and extension in educational area. After that, it is registered a reading of that production, indicating some of its characteristics: coherence in the commitment with educational inclusion; research as factor of organicity in the fields of Didactics and Teaching Education and interaction between them; emphasis in ethnographic research; participation in historical constitution of the mentioned fields of study. It is finished mentioning that Marli's collective and educative work implies a legacy which marks and will continue marking educational area.
\end{abstract}

KEYWODS: Marli André; Didactics and Teaching Education; educational research. 


\section{MARLI ANDRÉ - PERSONA SINGULAR, PROFESORA, INVESTIGADORA, ACADÉMICA, EN DIDACTIS Y FORMACIÓN DE PROFESORES CAMPOS DE ESTUDIO}

RESUMEN: Este texto tiene por objetivo homenajear a Marli André, abordando aspectos de su obra en la Didáctica y en la Formación de Profesores. Además de las marcas de una asociación común, se tuvo como fuente producción intelectual de Marli y de autores que tratan de la obra en pauta. Se presentan características del trabajo realizado por ella en la administración, ensenãnza, investigación y extensión en la educación. A continuación, se hace uma lectura de la producción, indicando algunas de sus características: coherencia em el compromiso com la inclusión educational; investigación como factor de organicidad entre los campos de la Didáctica y de la Formación de Profesores y la interacción entre ellos; énfasis en la investigación etnográfica; participación en la constitución de los campos de estudio mencionados. Se termina afirmando el carácter colectivo y educativo de la obra de Marli, cuyo legado ha marcado y seguirá marcando el área educacional.

PALABRAS CLAVE: Marli André. Didáctica y Formación de Profesores. Investigación en educación. 


\section{Introdução}

O objetivo deste texto é o de contribuir com uma justa e merecida homenagem à Marli Elisa Dalmazo Afonso de André (a Marli, carinhosamente), explicitando marcas da nossa convivência. Esta foi construída em uma parceria de mais de trinta anos de atividades comuns e permeadas por influências intelectuais, profissionais e pessoais mútuas, envolvendo conversas acadêmicas, amigas, alegres e instigadoras.

Nessas condições, apresento aspectos da obra da Marli, pretendendo que eles não apenas contribuam para uma compreensão dessa, mas, também, sirvam de fonte para o contínuo desenvolvimento do conhecimento científico teórico-prático. Isso permeado pelo compromisso com uma educação socialmente referenciada, na Didática e na Formação de Professores. Assim, este texto salienta, de início, princípios e valores com os quais ela construía o seu trabalho, particularmente nesses campos. Princípios e valores que estão presentes em todo o trabalho e que transcendem em muito as suas referências bibliográficas em si mesmas consideradas.

A construção do texto, difícil, diga-se de passagem, pela saudade, ainda que doce, da presença física da amiga mais que querida, teve como base três critérios objetivo-subjetivos.

Um deles se refere à apresentação de aspectos de uma das leituras possíveis da extensa e profunda obra da Marli, profissional competente, generosa e ética nos âmbitos da administração, do ensino, da pesquisa e da extensão, na área educacional. Ela gostava de compartilhar seus escritos e suas apresentações em eventos, sem qualquer prepotência. Isso com os mais variados sujeitos históricos, pessoas da sua convivência e muito além dela, na direção de um projeto educativo, construído coletivamente e articulado com um projeto societário democrático e sem qualquer forma de exclusão.

Outro critério se insere no atendimento a características de um texto a ser publicado em um periódico científico. Marli não abria mão do valor dessas características, no desenvolvimento do conhecimento científico, particularmente na área da educação. Estava sempre atenta a elas nas suas próprias construções ou naquelas de seus alunos, colegas e amigos. Conversávamos sempre sobre produções acadêmicas na área. Também, com frequência, enviava-Ihe os meus textos ou dialogava com ela sobre eles, quando contava com sua apreciação cuidadosa, séria, profundamente respeitosa e que me empurrava para frente. Ela me passava coragem, desejo de acertar e contribuir com aquele projeto. Às vezes, também, ela discutia os seus textos comigo, com a humildade serena e inteligente de pesquisadora, o que confesso, implicava, para mim, uma responsabilidade difícil de contemplar, dada a qualidade do seu trabalho e a sua terna amizade.

O terceiro critério, estreitamente relacionado aos anteriores, refere-se à pergunta que me fiz: o quê a amiga esperaria deste/neste texto, de forma a implicar uma contribuição para o entendimento e a continuidade do seu trabalho cujo valor inestimável contribui para o nosso crescimento como pessoas humanas, sujeitos históricos e profissionais intelectuais críticos na área da educação. Na década de 1990, em uma abordagem que fiz da então já expressiva produção intelectual da autora, e que passei para ela apreciar, ela me disse, não exatamente com estas palavras: você me ajuda a entender os meus próprios estudos. Dói-me saber que não vou poder ouvir dela a apreciação de aspectos da leitura da sua obra que apresento neste texto. Que aqueles que a leiam possam avaliá-la com o rigor e a generosidade com os quais ela o faria.

Com base nos critérios expostos, optei por abordar parte da produção intelectual da autora que favorece entendimento da construção do seu trabalho, envolvendo diferentes momentos históricos. Isso será precedido por uma breve e primeira aproximação, em que busquei, em minhas memórias, marcas da convivência 
com a amiga, em várias das nossas atividades conjuntas. Entre estas saliento as realizados na Associação Nacional de Pós-Graduação e Pesquisa em Educação (ANPEd), nas comissões de agências financiadoras da pesquisa e da pós-graduação no país, em eventos acadêmicos, na produção intelectual e sua divulgação. Essas marcas, cujo registro se faz tímido face à grandeza da obra em pauta, evidenciam os seus fios condutores coerentemente entrelaçados nos âmbitos da administração, do ensino, da pesquisa e da extensão.

\section{Uma primeira aproximação}

De início, importa situar a presença da Marli, quer na Diretoria da ANPEd, quer como membro dos Grupos de Trabalho (GT), inicialmente no GT de Didática, do qual foi coordenadora e membro do Colegiado, e, posteriormente, no GT de Formação de Professores. Nesse contexto, ela fazia questão de acolher todos os membros históricos e abrir caminhos para os novos que chegavam, com uma condução democrática e estimuladora das atividades da Associação em geral e dos seus GTs. Sua vinculação aos dois GTs mencionados, por si só, já sinaliza a sua presença frequente no desenvolvimento do conhecimento teórico-prático da Didática e da Formação de Professores.

A sua atividade como coordenadora do Comitê Assessor da Área de Educação no Conselho Nacional de Desenvolvimento Científico e Tecnológico (CNPq) e na Comissão de Avaliação da Pós-graduação stricto sensu da Coordenação de Aperfeiçoamento de Pessoal de Nível Superior (CAPES), na área da educação, reitera o exposto. Vale lembrar o seu papel na apreciação de pesquisas relacionadas sobretudo aos temas de ensino e aprendizagem e da formação de professores, no CNPq. Além disso, a sua participação na formação de pesquisadores com uma estreita relação entre ensino e pesquisa, presente e defendida por ela em todas as suas ações, fica também exemplificada naquela comissão da CAPES. Assim, à característica anterior, salienta-se outra: a defesa da importância da pesquisa na construção do conhecimento educacional. Podese afirmar, com Paulo Freire, em seu livro Pedagogia da Autonomia (Freire, 1996), que para a Marli ensino e pesquisa estavam sempre juntos.

Em estreita relação com as atividades mencionadas, no âmbito da extensão, Marli se fez presente, por exemplo, em vários eventos, entre os quais cumpre salientar o Seminário A Didática em Questão (SDE) e - Encontro Nacional de Didática e Prática de Ensino (ENDIPE). Os textos, apresentados individualmente ou em coautoria, são importantes para compreensão da sua obra, como fica claro pelos seus títulos registrados no Quadro 01.

Quadro o1 -Textos de Marli André nos eventos SDE e ENDIPE - 1985-2018.

\begin{tabular}{|c|c|l|}
\hline \multicolumn{2}{|c|}{ SDQ/Endipe } & \multicolumn{1}{c|}{ Título } \\
\hline III & 1985 & Em busca de uma didática fundamental \\
\hline IV & 1987 & A pesquisa no cotidiano da escola e o repensar da didática \\
\hline V & 1989 & A evolução do ensino da didática no Brasil \\
\hline VII & 1994 & O papel da pesquisa na articulação entre saber e prática docente \\
\hline VIII & 1996 & Entre propostas... Uma proposta para o ensino da didática \\
\hline IX & 1998 & Desafios da pesquisa sobre a prática pedagógica \\
\hline X & 2000 & A pesquisa sobre formação de professores no Brasil 1900-1998 \\
\hline
\end{tabular}




\begin{tabular}{|c|c|l|}
\hline XI & 2002 & $\begin{array}{l}\text { O memorial: um instrumento de investigação do desenvolvimento } \\
\text { profissional do professor }\end{array}$ \\
\hline XIII & 2006 & $\begin{array}{l}\text { Ensinar a pesquisar... Como e para quê } \\
\text { Pesquisas sobre formação de professores: uma análise das } \\
\text { racionalidades } \\
\text { Processos psicossociais na formação de professores (coautoria) } \\
\text { O trabalho docente do professor formador (coautoria) }\end{array}$ \\
\hline XIV & 2008 & $\begin{array}{l}\text { Tendências da pesquisa e do conhecimento didático no início dos anos } \\
2000 \\
\text { A constituição da profissionalidade dos professores chefes de } \\
\text { departamento da licenciatura (coautoria) } \\
\text { Formação de professores, saberes docentes e os desafios da } \\
\text { profissionalidade (coautoria) }\end{array}$ \\
\hline XV & 2010 & $\begin{array}{l}\text { Formação docente e o trabalho do professor formador (coautoria) } \\
\text { Desafios na formação do pesquisador da prática pedagógica }\end{array}$ \\
\hline XVII & 2014 & $\begin{array}{l}\text { O desenvolvimento profissional de professores de cursos de } \\
\text { licenciatura, de coordenadores pedagógicos e de docentes iniciantes na } \\
\text { educação básica (coautoria) }\end{array}$ \\
\hline XIX & 2018 & \\
\hline
\end{tabular}

Fonte - Informações no currículo Lattes da autora e nas referêcias ao final deste texto.

Os dados do Quadro 01 mostram aqueles dois grandes campos de estudo para cujo desenvolvimento científico a autora contribui, de forma mais expressiva: a Didática e a Formação de Professores. Reitera-se, também, a importância atribuída à prática da pesquisa na constituição científica desses campos e no estreitamento da relação teoria e prática, sem deixar de reconhecer os desafios na pesquisa e na formação do pesquisador, no âmbito da prática pedagógica. Além disso, Marli não deixa de tratar do ensino, propriamente dito, quer na Didática, quer na condição geral da formação dos professores. Pode-se indicar o seu envolvimento com a teoria da prática, a prática da pesquisa e a prática do ensino em ambos os campos.

Finalmente, há que se registrar a atividade da autora na coordenação da Série Prática Pedagógica, da editora Papirus, que vai ao encontro da sua característica de também contribuir para a democratização do conhecimento na educação. Aqui vale lembrar a sua opção pela centralidade da prática no conhecimento pedagógico, o que se expressa pelo título da Série mencionada. Acompanhei de perto essa decisão que muito se deveu à posição dela de colocar em evidência a prática pedagógica na construção científica na área da educação e das ciências humanas. A propósito, os livros publicados, muitos dos quais sob a sua coordenação, reiteram seus temas de estudo, sem deixar de acolher novos temas por vezes emergentes, naquelas áreas.

\section{Outros fios da obra da Marli na Didática e na Formação de Professores}

Apresenta-se, aqui, de forma geral, características da produção intelectual da Marli, que me propus a indicar na escrita deste texto. Para isso, tive como fontes principais e com caráter amostral, além das atividades 
mencionadas, algumas análises dos seus estudos, feitas por ela própria (ANDRÉ, 1992) ou por outros autores (OLIVEIRA, 1993, 1995; FREITAS, 1994), na década de 1990. Além da releitura desse material, levantei os títulos dos textos apresentados por ela nos Encontros Nacionais de Didática e Prática de Ensino, envolvendo o período de 1985 a 2018, tal como registrado no Quadro 01. Acrescentei, ainda, como fontes: o conteúdo da homenagem feita no periódico Cadernos de Pesquisa (COMITÊ EDITORIAL, 2021) e o conjunto dos livros e capítulos da autora aos quais tive acesso mais imediato, envolvendo aquele período. Esse conjunto envolve todas as publicações indicadas nas referências bibliográficas deste texto, que apresenta uma síntese do seu conteúdo.

Importa lembrar que o conteúdo e a abordagem do presente texto contam com muito que aprendi com a própria Marli. Não tenho dúvidas de que a leitura que faço é uma das possíveis da obra aqui tratada, a partir de uma amostra e do caráter geral com o qual foi abordada, nos limites objetivo-subjetivos da construção deste texto.

Dentro desses limites, foram abordados alguns aspectos que considero essenciais na obra aqui tratada e que nela são igualmente importantes. A rigor, entendo que esses aspectos, apresentadas juntos e de forma sistemática neste texto, são reconhecidos como tal pela comunidade acadêmica. Eles estão presentes no conjunto da produção intelectual analisada. Nesse sentido, as referências bibliográficas indicadas, a seguir, são apenas sinalizações mais específicas de cada um.

\section{Coerência no compromisso com a inclusão educacional}

Há que se registrar o caráter de coerência intelectual da professora pesquisadora. Não raro, ela retoma, em novas discussões, estudos realizados em momentos diferentes da carreira. Um exemplo é o da sua dissertação de mestrado de 1976 (ANDRÉ, 1976) relembrada quando da discussão da pedagogia das diferenças em livro de 1999 (ANDRÉ, 1999a, 1999b; ANDRÉ; DARSIE, 1999). Nesses estudos, ficam claros o compromisso com a inclusão educacional e a sensibilidade para questões relativas a ela. É apropriado lembrar que, no decorrer das suas pesquisas ocorre a discussão, na década de 1990, do enfrentamento do fracasso escolar e de novas práticas avaliativas na escola. Já na década anterior estudava-se sobre professores das camadas populares, a prática pedagógica bem sucedida e, no contexto da construção de uma Didática Fundamental, Marli (ANDRÉ, 1988a, p.148) afirmava o compromisso "com a transformação social e a construção de práticas pedagógicas adequadas às crianças das classes economicamente desfavorecidas." Esse compromisso expressa-se, também, em seus estudos que tratam explicitamente da aproximação entre universidade e escola básica, como os da última década, tal como em André (2016b).

\section{Pesquisa como fator de organicidade e a interação entre Didática e Formação de Professores}

Uma das características da obra refere-se também à integração entre Didática e Formação de Professores, cuja organicidade Ihes é atribuída pela presença marcante da pesquisa na construção teórico-prática de ambos. Assim, de fato, o foco principal dos estudos da autora, na Didática, nas décadas anteriores a de 2000, desloca-se a partir do início dessa década para a Formação de Professores. No entanto, o fio condutor da pesquisa no ensino, na prática pedagógica das escolas, na formação de professores permanece constante. Não é sem razão que os estudos realizados incluem o papel didático da pesquisa na Didática (ensino de didática) e na formação do professor em geral, o que reforça também aquela característica da relação estreita entre ensino e pesquisa na produção teórico-prática analisada (ANDRÉ, 1988b, 1997a, 2001a, 2001b, 2014, 2016a). Dentro disso, a interação entre os dois campos indicados aparece presente, quer pelo estudo da 
produção do conhecimento didático nos cursos de formação de professores (ANDRÉ; CRUZ, 2013), quer pela própria indagação sobre a autonomia da Formação de Professores como um campo de estudo autônomo em relação ao da Didática. Neste caso, André (2009, p.241) pergunta: "a formação de professores é um campo de estudos autônomo ou uma subárea da Didática?".

\title{
3. Ênfase na pesquisa etnográfica
}

Ao lado das características mencionadas, a pesquisa etnográfica aparece como uma constante nos estudos sobre a Formação de Professores e, de forma mais enfática, sobre Didática (ANDRÉ, 1995; LUDKE; ANDRÉ, 1986).

A propósito, a abordagem antropológica etnográfica é bem utilizada na pesquisa nesses campos, evidenciada, por exemplo, pelo fato de que o livro Etnografia da prática escolar (ANDRÉ, 1985) ser aquele que conta com maior número de edições na Série Prática Pedagógica.

No entanto, é no âmbito da Didática que a autora faz a defesa explícita desse tipo de pesquisa, envolvendo o estudo do cotidiano escolar, nas décadas de 1980 e 1990. Isso, particularmente, no contexto do movimento A Didática em Questão, iniciado e coordenado por Candau (1988), e do qual Marli participou ativamente. Nessa condição, ela afirma, no IV ENDIPE, DE 1997, que a pesquisa em pauta pode:

\begin{abstract}
... apontar elementos importantes relacionados à prática pedagógica de sala de aula que a literatura especializada deixa de enfatizar ou chega mesmo a omitir. (...) pode também revelar dimensões novas ou formas alternativas de enxergar e analisar o ato docente. (...) pode de forma muito direta e imediata afetar o trabalho da própria escola onde foi realizada. (ANDRÉ, 1987, p.90-91).
\end{abstract}

Já na década de 2000, ao estudar as pesquisas sobre Formação de Professores, a autora não deixa de lembrar a histórica presença das abordagens qualitativas nesse campo, embora levante uma questão: "Os estudos quantitativos parecem estar retornando com muita credibilidade. Estaremos nos deparando com um novo conflito de métodos?" (ANDRÉ, 2009, p. 248).

Participação expressiva na constituição histórica da Didática e da Formação de Professores e os estudos integrativos

A autora companha a construção desses campos com a qual contribui de forma expressiva. Pelo já exposto, fica clara a sua presença na reconstrução da Didática numa perspectiva não tecnicista (ANDRÉ; MEDIANO, 1988). A propósito, no ENDIPE de 1989, tem-se:

... a necessidade de que a didática leve em conta a realidade concreta das nossas escolas, seus, problemas, seus dilemas e suas descobertas; o apelo para a incorporação dos resultados das pesquisas que vem se desenvolvendo sobre o cotidiano escolar; a importância da articulação entre "a didática vivida e a didática pensada, trazendo à baila a questão medular da articulação entre teoria e prática. (ANDRÉ, 1989, p.7).

Na Didática, Marli amplia suas discussões para o ensino de Didática, propriamente dito, tal como tratado em André (1997b) e André e Oliveira (1997c, 1997d). 
Na Formação de Professores, ela também se faz presente de forma evidente quando, por exemplo, na década de 2010, trata das políticas de iniciação à docência. Nessa construção, sem abandonar a perspectiva etnográfica nos estudos indicados, passa-se a enfatizar, apropriadamente, a pesquisa do tipo integrativo (como os estados da arte). Mas, a rigor, nos dois campos de estudo, dando visibilidade à sua atenção para o caráter histórico do conhecimento científico. E com isso, há a introdução de novos temas que se mostram, de forma rigorosa e crítica, contemporâneos na contemporaneidade, tratando, por exemplo, de práticas inovadoras na área da educação (ANDRÉ, 2016c).

\section{Últimas palavras}

Os aspectos anteriores parecem, de fato, serem fundamentais na caracterização do trabalho da autora. No entanto, eles vêm permeadas por duas características chaves. Uma delas é o trabalho coletivo em que a autora elabora textos em coautoria, forma grupos de pesquisa e organiza livros com vários autores do país e do exterior. Finalmente, tudo isso é parte expressiva do seu legado fundamental na área da educação, ou seja, o seu caráter essencialmente educativo e pedagógico.

Finalmente, não é demais lembrar o fato de que o conteúdo e a forma deste texto implicam limites próprios das condições objetivo-subjetivas da sua elaboração pelas fontes indicadas que têm caráter amostral. Deseja-se que o estudo da obra em pauta seja completado e divulgado, pela sua reconhecida contribuição na Didática e na Formação de Professores.

A despeito do seu caráter amostral, entende-se que a análise aqui feita conta com um grau bem razoável de compreensão do trabalho em pauta, considerando sobretudo a minha convivência muito próxima com a autora, com quem discutia questões de Didática e Formação de Professores.

Termino, lembrando que, nos Cadernos de Pesquisa (COMITÊ EDITORIAL, 2021), em homenagem à Marli, mais de um dos textos faz menção à sua sempre presença entre nós. Reitero que ela esteve sempre conosco e assim continuará, com o legado que construiu de forma competente e generosa. 


\section{Referências}

ANDRÉ, M.E.D.A. A contribuição no estudo de caso etnográfico para a reconstrução da didática.1992.132f. Tese (Livre docência em Educação) Universidade de São Paulo - São Paulo, 1992.

ANDRÉ, M.E.D.A. A contribuição da pesquisa etnográfica para a construção do saber didático. In: OLIVEIRA, M.R.N.S. (Org.). Didática: ruptura, compromisso e pesquisa. Campinas: Papirus, 1995, p.109-120.

ANDRÉ, M.E.D.A. Desafios na formação do pesquisador da prática pedagógica. In: ENCONTRO NACIONAL DE DIDÁTICA E PRÁTICA DE ENSINO, XVII, 2014, Fortaleza. Caderno da programação. Fortaleza, UECE, 2014. p.18.

ANDRÉ, M.E.D.A. Em busca de uma didática fundamental. In: CANDAU, V.M. Rumo a uma nova didática. Petrópolis, Vozes, 1988a.

ANDRÉ, M.E.D.A. A evolução do ensino de didática no Brasil. In: V ENCONTRO NACIONAL DE DIDÁTICA E PRÁTICA DE ENSINO, Belo Horizonte,1989. (mimeo).

ANDRÉ, M.E.D.A. Etnografia da prática escolar. Campinas, Papirus, 1985.

ANDRÉ, M.E.D.A. Formar o professor pesquisador para um novo desenvolvimento profissional. In: ANDRÉ, M.E.D.A. (Org.). Práticas inovadoras na formação de professores. Campinas: Papirus, 2016a, p. 17-34.

ANDRÉ, M.E.D.A. Um micro estudo do tempo instrucional e da estratégia de aprendizagem para o domínio, 1976. Dissertação (Mestrado em Educação) Pontifícia Universidade Católica do Rio de Janeiro - Rio de Janeiro, 1976.

ANDRÉ, M.E.D.A. O papel mediador da pesquisa no ensino de didática. In: ANDRÉ, M.E.D.A., OLIVEIRA, M.R.N.S. (Orgs.). Alternativas no ensino de didática. Papirus, 1997a, p. 19-36.

ANDRÉ, M.E.D.A. (Org.). O papel da pesquisa na formação e na prática dos professores. Campinas, Papirus, $2001 \mathrm{a}$.

ANDRÉ, M.E.D.A. A pedagogia das diferenças. In: ANDRÉ, M.E.D.A. (Org.). Pedagogia das diferenças na sala de aula. Campinas: Papirus, 1999a, p.11-26.

ANDRÉ, M.E.D.A. (Org.). Pedagogia das diferenças na sala de aula. Campinas, Papirus, 1999b.

ANDRÉ, M.E.D.A. A pesquisa no cotidiano da escola e o repensar da didática. Educação e Sociedade, São Paulo, v.9, n.27, p.84-92, set.1987.

ANDRÉ, M.E.D.A. A pesquisa na didática e na prática de ensino. In: CANDAU, V.M. (Org.). Rumo a uma nova didática. Petrópolis, Vozes, 1988b, p,169-179.

ANDRÉ, M.E.D.A. Pesquisa, formação e prática docente. In: ANDRÉ, M.E.D.A. (Org.). O papel da pesquisa na formação e na prática dos professores. Campinas: Papirus, 2001b, p.55-70. 
ANDRÉ, M.E.D.A. Pesquisas em formação de professores: contribuição para a prática docente. In: PINHO, S.Z. (Org.). Formação de educadores: o papel do educador e sua formação. São Paulo, Editora Unesp. 2009, p. 241-250.

ANDRÉ, M.E.D.A. Políticas de iniciação à docência para uma formação profissional qualificada. In: ANDRÉ, M.E.D.A. (Org.). Práticas inovadoras na formação de professores. Campinas: Papirus, 2016b, p. 49-70.

ANDRÉ, M.E.D.A. (Org.). Práticas inovadoras na formação de professores. Campinas, Papirus, 2016c.

ANDRÉ, M.E.D.A. Tendências no ensino de didática no Brasil. In: PIMENTA, S.G. (Org.). Didática e formação de professores: percursos e perspectivas no Brasil e em Portugal.São Paulo: Cortez, 1997b, p.191-204.

ANDRÉ, M.E.D.A., CRUZ, G.B. A produção do conhecimento didático e a formação de professores no Brasil. In: OLIVEIRA, M.R.N.S., PACHECO, J.A. (Orgs.). Currículo, didática e formação de professores. Campinas, Papirus, 2013, p. 167-191.

ANDRÉ, M.E.D.A.; DARSIE, M.M.P. Novas práticas de avaliação e a escrita do diário: atendimento às diferenças? In: ANDRÉ, M.E.D.A. (Org.). Pedagogia das diferenças na sala de aula. Campinas: Papirus, 1999, p.11-26.

ANDRÉ, M.E.D.A.; MEDIANO, Z. O cotidiano da escola: elementos para a construção de uma didática fundamental. In: CANDAU, V.M. (Org.). Rumo a uma nova didática. Petrópolis, Vozes, 1988. P.157-168.

ANDRÉ, M.E.D.A; OLIVEIRA, M.R.N.S. (Orgs.). Alternativas no ensino de didática. Campinas, Papirus, 1997c.

CANDAU, V.M. (Org.). Rumo a uma nova didática. Petrópolis, Vozes, 1988.

COMITÊ EDITORIAL. Marli André (1944-2021). Cadernos de Pesquisa, São Paulo, v. 51, e08775, abr. 2021. Disponível em https:publicacoes. fcc.org.br//index.php/cp

FREITAS, L.C. Críticas da organização do trabalho pedagógico e da didática, 1994. 304f. (Livre docência em Educação) Unicamp - Campinas, 1994

LUDKE, M \& ANDRÉ, M.E.D.A. Pesquisa em educação: abordagens qualitativas. São Paulo, EPU, 1986.

OLIVEIRA, M.R.N.S. A reconstrução da didática: elementos teórico-metodológicos. Campinas, Papirus, 1993.

OLIVEIRA, M.R.N.S. (Org.). Didática: ruptura, compromisso e pesquisa. Campinas, Papirus, 1995.

OLIVEIRA, M.R.N.S., ANDRÉ, M.E.D.A. A prática do ensino de didática no Brasil: introduzindo a temática. In: ANDRÉ, M.E.D.A., OLIVEIRA, M.R.N.S. (Orgs.). Alternativas no ensino de didática. Papirus, 1997d. p. 7-18.

OliveirA, N. S. M. R. Marli André - Pessoa Singular, Professora, Pesquisadora, Acadêmica, nos campos da didática e da Formação de Professores Formação Docente - Revista Brasileira de Pesquisa sobre Formação de Professores. Belo Horizonte. Vol. 13, no .28 (p. 57-66) 31 dez. 2021. ISSN: 2176-4360. doi https://doi.org/10.31639/rbpfp.v13i28.516 